\title{
Determining Redundancy of Short-day Onion Accessions in a Germplasm Collection Using Microsatellite and Targeted Region Amplified Polymorphic Markers
}

\author{
Theodore J. Kisha ${ }^{1,3}$ \\ USDA-ARS, Western Regional Plant Introduction Station, 59 Johnson Hall, Washington State \\ University, Pullman, WA 99164 \\ Christopher S. Cramer ${ }^{2}$ \\ Department of Plant and Environmental Sciences, MSC 3Q, Box 30003, New Mexico State University, \\ Las Cruces, NM 88003-8003
}

\begin{abstract}
AdDitional INDEX wORDs. diversity, genetic resource management, STRUCTURE
Abstract. The U.S. National Plant Germplasm System is one of the world's largest national genebank networks focusing on preserving the genetic diversity of plants by acquiring, preserving, evaluating, documenting, and distributing crop-related germplasm to researchers worldwide. Maintaining viable germplasm collections is essential to world food security but comes at a cost. Redundancy within the collection can incur needless expense and occurs as a result of donations of similar material under different names from different donors. Alternatively, similarly named accessions from different donors can actually be genetically distinct. We evaluated 35 short-day onion (Allium cepa) accessions using microsatellite and targeted region amplified polymorphic (TRAP) molecular markers to compare newly acquired germplasm with existing accessions in the collection to determine differences and redundancies and to compare the use of each marker type in distinguishing the onion accessions. Both marker types distinguished differences and found similarities, but the results did not always agree. TRAP markers found one of the Italian Torpedo entries to be different, whereas the $\mathbf{1 0}$ microsatellite loci analyzed found no differences. In contrast, microsatellite analysis found all three Red Grano entries to be different, whereas TRAP analysis distinguished only one accession. The eight White Grano entries were separated into four groups by microsatellite markers and five groups by the TRAP markers. Discriminating among closely related accessions using molecular markers can require a large number of random marker loci, especially when differences may be limited to a single trait. TRAP markers were more efficient, uncovering $\approx 10$ random polymorphic loci per primer pair, whereas microsatellite markers each uncovered differences at a single locus.
\end{abstract}

The U.S. National Plant Germplasm System (NPGS) is one of the world's largest national genebank networks focusing on preserving the genetic diversity of plants by acquiring, preserving, evaluating, documenting, and distributing crop-related germplasm to researchers worldwide. Among the over 500,000 accessions of plant germplasm managed through the NPGS, $\approx 1100$ accessions are of cultivated onion. Specific challenges for germplasm repositories include minimizing genetic change during seed increase, limiting redundancy in the collection, and maximizing genetic diversity in a collection that remains manageable in size. Maintaining viable germplasm collections is essential to world food security but comes at a cost. Redundancy within the collection can incur needless expense and occurs as a result of donations of similar material under different names from different donors. Alternatively, similarly named accessions from different donors can actually be genetically distinct. Thus,

Received for publication 30 Sept. 2010. Accepted for publication 10 Dec. 2010. This research was funded through a germplasm evaluation grant from the National Plant Germplasm System, ARS, USDA.

Mention of product names does not represent an endorsement of any product or company but is given only to clarify the methodology; other products may be equally effective.

${ }^{1}$ Plant Geneticist.

${ }^{2}$ Professor of Horticulture

${ }^{3}$ Corresponding author. E-mail: tkisha@wsu.edu. detection of genetic differences among accessions is particularly critical at germplasm repositories, which are uniquely challenged to develop collections that represent the genetic diversity of the crop species.

Molecular markers have become an accepted and widely used tool for the measurement of genetic diversity, population structure, and evolution (Avise, 1994; Nei, 1987). Molecular marker technology can be used to characterize the extent of diversity within a collection and for the development of collection management strategies, which may include establishment of core collections (Gouesnard et al., 2001; Johnson et al., 2002; Marita et al., 2000), guidance for future collection efforts, and identification of gaps within collections of ancestral crop relatives. Additionally, analysis of worldwide genetic diversity can identify areas suited for the establishment of in situ conservation sites (Greene et al., 2008).

Microsatellite markers, or simple sequence repeats [SSRs (Oliveira et al., 2006; Tautz and Renz, 1984)], are codominant polymorphic markers formed by 2- to 6-bp repeats flanked by conserved regions that can serve as primer sequences. Marker production using the polymerase chain reaction (PCR) can result in markers with high polymorphism information content (Anderson et al., 1993), but single reactions usually result in analysis at only one locus, which increases laboratory costs and limits the number of loci compared. Amplified fragment length 
polymorphism (AFLP) markers produce many dominant markers with a single PCR reaction (Vos et al., 1995). Although less informative of genetic variability within a locus, they allow for the efficient sampling of many loci (Gaudeul et al., 2004; Powell et al., 1996). Thus, AFLPs lend themselves to studies when more loci are needed to estimate differences between populations (Mariette et al., 2002). Despite being dominant markers, AFLPs have shown themselves to be effective in discriminating among populations and correctly assigning individuals to populations when compared with SSRs (Gaudeul et al., 2004; Woodhead et al., 2005). However, the production and scoring of AFLP markers in a genome as large as that of Allium species is problematic (Volk et al., 2004).

Targeted region amplification polymorphism markers are amplified regions of polymorphic DNA between primers designed after specific gene analogs but that generate multiple fragments in a single PCR reaction (Hu and Vick, 2003). Using a "fixed" primer designed from a known gene sequence, a "random" primer with AT- or GC-rich cores designed to amplify intragenic fragments ( $\mathrm{Li}$ and Quiros, 2001), and less-stringent annealing temperatures, multiple, easily discernible polymorphic markers can be generated that are generally distributed randomly across the genome of interest (van Treuren and van Hintum, 2009).

A recently conducted, short-day onion germplasm plant exploration resulted in the collection of 70 to 75 lines that may be included in the onion collection to expand the number of short-day accessions. Some of the newly collected lines appear to be represented currently in the collection based on similar cultivar names of the newly collected lines and existing accessions. The inclusion of duplicate cultivars in the collection would result in additional cost for maintenance and regeneration without the benefit of additional genetic diversity. However, if the newly collected lines are different from existing accessions in the collection, even if similar cultivar names would suggest otherwise, then these newly collected lines should be included in the collection. A study to examine the relatedness of these newly collected lines to existing accessions currently in the collection would be helpful in deciding whether the collected material should be added or discarded. In addition to possible duplication of the newly collected lines, there are short-day onion accessions that share similar cultivar names. It is unclear whether these accessions represent different germplasm or are the same germplasm but with somewhat different cultivar names. A study to determine the relatedness of these existing accessions based on molecular marker data will be helpful in determining whether the accessions are unique or should be discarded as redundant.

The objective of this study was to use molecular markers to evaluate newly collected, short-day onion lines and to compare that germplasm with existing accessions in the collection to determine if including that germplasm in the collection would result in redundancy. In addition, this project evaluated shortday accessions in the collection that appear to have similar cultivar names to determine if some accessions are redundant and compared the efficacy of SSR and TRAP markers toward this end.

\section{Materials and Methods}

Plant material. Entries, accessions and collected germplasm, were separated into eight groups (Eclipse, Italian Red Torpedo, Red Creole, Red Grano, White Creole, White Grano,
White Mexican, and Yellow Grano) based on their cultivar name relatedness (Table 1). Entries in the Eclipse group of onions (U.S. Department of Agriculture, 2010) are very similar to 'Crystal White Wax', which was developed from 'White Bermuda' (Goldman et al., 2000). Onions produced by these cultivars tend to be early-maturing, medium to large in size, flat-shaped, of short storage, and possess a shiny, white dry outer scale and a mild-flavored, soft flesh (Magruder et al., 1941). Cultivars of the Italian Red Torpedo group produce a very characteristic onion bulb that is oblong in shape, has reddish purple dry outer scales, and white, mild-flavored fleshy scales. Creole-type onions are thought to be tropical in nature because they have a short-day to almost day-neutral bulbing response that would suggest adaptation to lower latitudes. Bulbs of Creole cultivars store for long periods of time, are small to medium in size, and have a flattened shape and pungent fleshy scales. Red Creole and White Creole cultivars produce bulbs that have reddish and shiny white dry outer scales, respectively. Bulbs produced from Grano-type cultivars tend to be large in size and top-shaped. The bulbs have mild-flavored fleshy scales and they store for short periods of time.

Bulbs of 'Red Grano', 'White Grano', and 'Yellow Grano' have reddish purple, shiny white, and pale yellow dry outer scales, respectively. Grano-type onions are thought to have arisen from 'Babosa' or 'Valencia Grano' onions that were imported from Spain to New Mexico in the early 20th century (Goldman et al., 2000). Breeding work at this time in New Mexico resulted in the development of cultivars from 'New Mexico Early Grano' (Garcia and Fite, 1931; Goldman et al., 2000). 'New Mexico Early Grano' was taken to Texas from which 'Texas Early Grano' was developed (Goldman et al., 2000). This cultivar served as the progenitor for 'Texas Grano', 'Texas Early Grano 502', and 'Crystal Grano' (Goldman et al., 2000). 'Texas Early Grano 502 PRR' was a pink root (Phoma terrestris) -resistant selection of 'Texas Early Grano 502'. Some additional material must have been introgressed into 'Texas Early Grano 502 PRR' because 'Texas Early Grano 502' possesses normal cytoplasm exclusively and 'Texas Early Grano 502 PRR' possesses sterile cytoplasm exclusively (Havey and Bark, 1994). 'White Mexican' is an onion cultivar that is adapted to the Tampico District of Mexico. Bulbs from this cultivar have a flat shape, short storage length, and pungent flesh.

DNA EXtraction. Seeds of all accessions were grown in a greenhouse in Pullman, WA. Sixteen seedlings from each accession were sampled and tissue was freeze-dried and placed in a $1.5-\mathrm{mL}$ microcentrifuge tube with six 3-mm-diameter glass beads. Tubes were placed in a plastic tube rack and shaken in a Geno/Grinder 2000 (SPEX SamplePrep, Metuchen, NJ) until pulverized. Extraction of DNA was completed using the MagneSil ${ }^{\circledR}$ kit (Promega, Madison, WI).

Simple SEQUENCE REPEAT MARKERS. A total of 10 SSR primer pair loci were examined (ACM006, ACM013, ACM017, ACM078, ACM082, ACM091, ACM093, ACM097, ACM099, ACM102) with forward and reverse primer sequences reported by Jakše et al. (2005). Loci were selected that amplified 3-bp repeats to avoid stutter bands. The three-primer system developed by Boutin-Ganache et al. (2001) was used to reduce cost for labeled primers. The sequence TGTAAAACGACGGC CAGT was added to the $5^{\prime}$ end of each forward primer selected from Jakše et al. (2005). Reaction volume was $10 \mu \mathrm{L}$ and contained 0.1 unit of Biolase ${ }^{\mathrm{TM}}$ Taq polymerase (Bioline, Boston, $\mathrm{MA}) ; 25 \mathrm{ng}$ of template DNA; and reagent concentrations of 
Table 1. Onion accessions and collected short-day onion germplasm evaluated for redundancy arranged by classification group.

\begin{tabular}{|c|c|}
\hline Entry name $^{z}$ & Seed source ${ }^{y}$ \\
\hline \multicolumn{2}{|l|}{ Eclipse } \\
\hline 'Eclipse L303’ (PI 546119) & Dessert Seed Co. \\
\hline 'Eclipse' CSC & Condor Seed Production \\
\hline 'Eclipse' ESC & Emerald Seed Co. \\
\hline \multicolumn{2}{|l|}{ Italian Red Torpedo } \\
\hline 'Long Red Italian’ (PI 546168) & Ferry-Morse Seed Co. \\
\hline 'Red Torpedo' IVS & Imperial Vegetable Seeds \\
\hline 'Italian Red Torpedo' LS & Lockhart Seeds \\
\hline \multicolumn{2}{|l|}{ Red Creole } \\
\hline 'Red Creole C-5’ (PI 546180) & $\begin{array}{l}\text { Louisiana State University/Dessert } \\
\text { Seed Co. }\end{array}$ \\
\hline 'Red Creole' CSC & Condor Seed Production \\
\hline 'Red Creole' ESC & Emerald Seed Co. \\
\hline 'Red Creole C-5' ESC & Emerald Seed Co. \\
\hline \multicolumn{2}{|l|}{ Red Grano } \\
\hline ‘Red Grano’ (PI 546234) & Dessert Seed Co. \\
\hline 'Red Grano’ ESC & Emerald Seed Co. \\
\hline ‘Red Grano’ IVS & Imperial Vegetable Seeds \\
\hline \multicolumn{2}{|l|}{ White Creole } \\
\hline ‘White Creole' (PI 385949) & Kirchoffs East Africa \\
\hline ‘White Creole’ (PI 546128) & Dessert Seed Co. \\
\hline 'White Creole' CSC & Condor Seed Production \\
\hline 'White Creole' ESC & Emerald Seed Co. \\
\hline 'White Creole PRR' SDF & Sensient Dehydrated Flavors \\
\hline \multicolumn{2}{|l|}{ White Grano } \\
\hline ‘Early White Grano’ (PI 546094) & Ferry-Morse Seed Co. \\
\hline 'S-1 White Grano' (PI 546161) & Waldo Rohnert Co. \\
\hline ‘White Grano’ (PI 546170) & Ferry-Morse Seed Co. \\
\hline 'New Mexico White Grano PRR' (PI 546271) & Dessert Seed Co. \\
\hline 'Extra Early White Grano’ MD & M. Dessert \\
\hline 'White Grano' CSC & Condor Seed Production \\
\hline 'White Grano’ ESC & Emerald Seed Co. \\
\hline ‘White Grano Improved’ MD & M. Dessert \\
\hline \multicolumn{2}{|l|}{ White Mexican } \\
\hline ‘White Mexican’ ESC & Emerald Seed Co. \\
\hline ‘White Mexican’ IVS & Imperial Vegetable Seeds \\
\hline \multicolumn{2}{|l|}{ Yellow Grano } \\
\hline ‘Texas Early Grano 502 PRR’ (G 32071) & Ferry-Morse Seed Co. \\
\hline 'Texas Early Grano 502' (G 32072) & Ferry-Morse Seed Co. \\
\hline ‘Early Texas Yellow Grano’ (PI 546110) & Seed Research Specialists \\
\hline 'Early Yellow Grano Texas 502’ (PI 546111) & Seed Research Specialists \\
\hline 'Texas Early Grano 502' (PI 546127) & Texas A\&M University/Dessert Seed Co. \\
\hline ‘New Mexico Yellow Grano’ (PI 546153) & New Mexico Crop Improvement Assn. \\
\hline 'Texas Grano 502 PRR' (PI 546261) & $\begin{array}{l}\text { Texas A\&M University/Asgrow Seed } \\
\text { Co./USDA-ARS-NCGRP }\end{array}$ \\
\hline
\end{tabular}

${ }_{\mathrm{z} P R R}=$ pink root-resistant.

y Asgrow Seed Co., Kalamazoo, MI (Monsanto Vegetable Seeds, Oxnard, CA); Condor Seed Production, Yuma, AZ; Desert Seed Co., El Centro, CA (Nunhems USA, Parma, ID); Emerald Seed Co., El Centro, CA; Ferry-Morse Seed Co., Mountain View, CA (Groupe Limagrain, Auvergne, France); Imperial Vegetable Seeds, El Centro, CA; Kirchoffs East Africa, Nairobi, Kenya; Lockhart Seeds, Stockton, CA; Louisiana State University, Baton Rouge; M. Dessert, El Centro, CA; New Mexico Crop Improvement Assn., Las Cruces, NM; Seed Research Specialists, Modesto, CA. (Groupe Limagrain); Sensient Dehydrated Flavors, Turlock, CA; Texas A\&M University, College Station; Waldo Rohnert Co., Gilroy, CA (Nunhems USA); U.S. Department of Agriculture, Agricultural Research Service, National Center for Genetic Resources Preservation (USDA-ARS-NCGRP), Fort Collins, CO.
$150 \mu \mathrm{M}$ each dNTP, $1.5 \mathrm{~mm} \mathrm{MgCl}_{2}$, and $0.2 \mu \mathrm{M}$ each of the forward and reverse primers. The amplification method started with an initial denaturing step at $94^{\circ} \mathrm{C}$ for $30 \mathrm{~s}$ followed by 15 cycles beginning at $94{ }^{\circ} \mathrm{C}$ for $10 \mathrm{~s}$, then to $65^{\circ} \mathrm{C}$ for $30 \mathrm{~s}$, and then to $72{ }^{\circ} \mathrm{C}$ for $30 \mathrm{~s}$ and stepping down the annealing temperature $1{ }^{\circ} \mathrm{C}$ at each cycle to finish at $50{ }^{\circ} \mathrm{C}$ and then ending with 10 cycles of $94{ }^{\circ} \mathrm{C}$ for $10 \mathrm{~s}$, then to $50^{\circ} \mathrm{C}$ for $30 \mathrm{~s}$, and then to $72{ }^{\circ} \mathrm{C}$ for $30 \mathrm{~s}$. Separation of the markers was done on a $6.5 \%$ polyacrylamide gel using a automated electrophoresis apparatus (GeneReadIR 4300; LI-COR Biosciences, Lincoln, $\mathrm{NE}$ ). Images were visualized using GeneImager Software (Scanalytics, Fairfax, VA) and fragments were scored by size.

TARGETED REGION AMPLIFIED POLYMORPHIC MARKERS. TRAP markers were generated according to $\mathrm{Hu}$ and Vick (2003) adjusted to $10 \mu \mathrm{L}$ reactions. Each reaction contained $1.5 \mathrm{mM} \mathrm{MgCl}_{2}, 200 \mu \mathrm{M}$ each dNTP, 2 pmol fixed primer, 0.2 pmol of each arbitrary primer, and 1 unit of Biolase $^{\mathrm{TM}}$ Taq polymerase with its associated buffer. The first combination of TRAP primers consisted of the fixed primer QHB14G14b and the random labeled primers Ga5 and $\mathrm{Sa} 12$ (Hu et al., 2005). The fixed primer, QHB14G14b, is from a sunflower (Helianthus annuus) expressed sequence tag (EST) with no homology to any known genes (Hu et al., 2005). The random primers, Sa12 and Ga5, were labeled with infrared (IR) dyes, IRD700 and IRD800 (Eurofins MWG Operon, Huntsville, AL), respectively. The second combination of TRAP primers consisted of the fixed primer miR 156a and random-labeled primers $\mathrm{Ga} 3$ and $\mathrm{Sa} 4$ (Maher et al., 2006). The random primers, Sa12 and Ga5, were labeled with IR dyes, IRD700 and IRD800, respectively. TRAP marker fragments were separated on a GeneReadIR 4300 on $6.5 \%$ polyacrylamide gel. Printed images were scored visually, markers being either present or absent.

Population differentiation. Accessions to be compared were grouped by individual plants, without a priori classification, into $K$ clusters using the software STRUCTURE, which identifies genetically 
similar populations based on genotypes in Hardy-Weinberg equilibrium (Falush et al., 2003, 2007; Pritchard et al., 2000; Pritchard and Rosenberg, 1999). The program assumes models with each run of $K$ hypothetical populations and assigns a probability $[P(X \mid K)]$ that individuals $(X)$ are correctly assigned to each of these $K$ populations. Each individual plant is then assigned a membership coefficient, the fraction of its genome assigned to each of the $K$ populations. Q-plots represent each individual by a thin horizontal line partitioned into $K$-colored segments that represent that individual's membership fractions in the $K$-estimated populations. Black lines separate individuals of different accessions.

Estimation of the most probable $K$ was facilitated by the technique developed by Evanno et al. (2005), which uses the change in the slope of the graph of $[P(X \mid K)]$ and the variance of the probability $[P(X \mid K)]$ at each value of $K$. Five replications with a burn-in length of 20,000 followed by a Markov chain Monte Carlo of 20,000 additional iterations were run at each assumed $K$ until results indicated lowered and erratic values for $[P(X \mid K)]$. The parameter set included the admixture model with allele frequencies correlated. Average Q-plots over all replications for the best $K$ and the resulting graphic display of ordered Q-plots were determined using the STRUCTURE ancillary programs CLUMPP (Jakobsson and Rosenberg, 2007) and DISTRUCT (Rosenberg, 2004), respectively.

\section{Results and Discussion}

Both marker types distinguished differences and found similarities, but the results did not always agree. Results of the STRUCTURE analysis for each of the groups of accessions is given as Q-plots in Figure 1. Both SSR and TRAP markers found 'Eclipse L303' to be distinct from the other Eclipse entries (Fig. 1A). Although SSRs found no differences among the Long Red Italian entries, TRAP markers distinguished 'Long Red Italian' (PI 546168) from the other two entries (Fig. 1B). The TRAP markers evaluated these accessions at 46 polymorphic loci. Dominant markers, because of the greater number of loci typically uncovered, have shown themselves to be effective in discriminating among populations and correctly assigning individuals to populations when compared with microsatellite markers (SSRs) (Gaudeul et al., 2004; Woodhead et al., 2005). In contrast, TRAP markers found no distinction among the Red Creole entries, whereas SSRs found 'Red Creole' C5 and 'Red Creole' CSC to be different from 'Red Creole' ESC and 'Red Creole C5' ESC (Fig. 1C). Prevosti's distance, which is a measure of the average allele frequency differences between the two pairs of entries (Prevosti et al., 1975) was 0.154 (data not shown). Still, STRUCTURE, which separates individuals into populations based on Hardy-Weinberg equilibrium, repeatedly placed these two pairs into different groups as a result of these differences.

Both marker systems found 'Red Grano' (PI 546234) to be different from the other Red Grano entries, but SSRs further distinguished the remaining two entries (Fig. 1D). Although the origins of the two commercial versions of 'Red Grano' are unknown, it is possible that differences observed between entries could have resulted from selection and/or genetic drift during seed production. Onion open-pollinated populations such as 'Red Grano' are very heterogenous between individuals and each individual within the population is quite heterozygous for most traits. With onions preferring to be cross-pollinated rather than self-pollinated, recombination among individuals during seed production would result in genetic variation not observed in the previous generation. In addition, onions are highly influenced by the environment in which they are grown. These environmental differences from one location to another can cause indirect selection and genetic drift of populations during seed production. This genetic drift could result in genetic differences between populations of the same cultivar if that cultivar was being produced by several different seed companies in several different locations.

Both marker systems found similar groupings among the White Grano entries (Fig. 1E). 'Early White Grano' (PI 546094) and 'White Grano' (PI 546170) were similar. 'White Grano' CSC, 'White Grano Improved', and 'White Grano' ESC formed a similar group, and 'Extra Early White Grano' was distinct. However, although SSRs found 'S-1 White Grano' (PI 546161) and 'New Mexico White Grano PRR' to be similar, TRAP markers separated the two entries. The results for the Yellow 
Grano entries differed from all the other analyses in that although both marker types found a significant break at $K=2$, the Q-plots did not divide those groups among entries. Rather, the Yellow Grano entries appeared to be an admixture of two populations (Fig. 1F). SSR alleles from the admixed populations showed a perceptible gradient from 'Texas Early Grano 502 PRR' developed by Ferry-Morse Seeds (Groupe Limagrain, Auvergne, France) to 'Texas Early Grano 502 PRR' developed by Asgrow Seed Co. (Monsanto Vegetable Seeds, Oxnard, CA). There was no perceptible gradient given by TRAP markers, but 'Texas Early Grano 502 PRR' developed by Asgrow Seed Co. was easily seen to be different from the rest of the accessions. This more clear delineation of this accession may have been the result of the greater number of loci analyzed by TRAP markers (31 polymorphic loci). There were no differences identified between the White Mexican entries or the White Creole entries by either marker system.

The results from this study found both differences and similarities among entries within each group. The decision whether to include or exclude newly collected lines or to remove redundant accessions ultimately rests with those individuals responsible for the collection. The goal of germplasm preservation is to maintain the greatest genetic diversity possible for a particular plant species. Although past policy has been to maintain every accession, knowledge of differences and similarities among accessions provides curators with tools to prioritize maintenance of accessions should resources become limiting. When subtle genetic differences among accessions may no longer be economically feasible to maintain, alternative methods to conserve diversity while reducing costs must be considered. One approach would be to combine closely related lines and/or accessions into a single line or accession that represents the cultivar in question. When this approach is taken, genetic diversity is maintained, whereas the number of lines or accessions is reduced. Another approach would be to designate the oldest, historical accession of the cultivar in question as the representative sample, maintain its genetic purity, and keep other representations only because they prove to be significantly different. As selection and genetic drift occur over time, newly acquired lines of a cultivar may diverge from the original cultivar. For example, the name Texas Early Grano 502 PRR would imply that this cultivar was only a pink root-resistant selection of 'Texas Early Grano 502'. This difference in itself might warrant the separation of the two cultivars. However, work by Havey and Bark (1994) suggested that the source of pink root resistance came from Excel $986 \mathrm{~A}$, a male-sterile line used in the development of the hybrid cultivar Granex 33, and possesses sterile-type (S) cytoplasm. In doing so, the PRR strains of 'Texas Early Grano 502' are almost exclusively S cytoplasm, whereas 'Texas Early Grano 502' populations are almost exclusively normal $(\mathrm{N})$ cytoplasm. This difference is important for the production of fertility restoration lines of 'Texas Early Grano 502' that have pink root resistance.

Decisions made with regard to germplasm maintenance must rely on as much information that a curator can bring to bear. Passport data, common garden studies, and molecular analyses all provide valuable information for curators and increase germplasm use for researchers and plant breeders requesting samples. The results shown here demonstrate both the strength and the shortfalls of molecular markers for distinguishing among accessions. Analysis at multiple loci can clearly distinguish among entries based on unique alleles or differences in allele frequencies.
However, when comparing closely related entries, the choice of marker systems or loci analyzed can ultimately determine the outcome. A near isogenic line, for example, can differ at one or a few loci, and the chances of choosing the marker locus associated with the important distinguishing trait can be remote if the differences and the linked marker are not known or suspected a priori. Subtle differences such as earliness or disease resistance can thus only be determined in a field study under which those differences are expressed. The advantages of TRAP markers are that they reveal more random loci in a single reaction and that if desired can also be directed toward specific traits. Miklas et al. (2006) used TRAP markers designed after ESTs associated with disease resistance in the Compositae Genomics Database or against sequenced resistance gene analogs from common bean (Phaseolus vulgaris). They found a proportion of the markers to map in the vicinity of $\mathrm{R}$ genes or to be linked with newly identified quantitative trait loci conditioning disease resistance in bean. Thus, TRAP markers designed for specific traits of interest could be used in conjunction with random genetic analysis to more specifically analyze differences among closely related accessions. In cases in which markers linked to specific differences are not known, random markers such as TRAPs with a high probability of wide genome coverage should be preferred.

In the present study, a conservative approach toward germplasm preservation is recommended, in which the curator would maintain accessions as different, even if only one marker set defined them so. For example, although the 'Long Red Italian' accession is distinguished by TRAP markers, but not the microsatellites, that accession should be considered as distinct from this study. All three Red Grano accessions should be considered as different, and the eight White Grano accessions should be maintained as five separate accessions. 'Texas Early Grano 502 PRR' is clearly different from the other six accessions. However, further investigation into the background of these accessions might be warranted. Overall, the need for complete and accurate passport data with the inclusion of entries into the germplasm system cannot be overstated.

\section{Literature Cited}

Anderson, J.A., G.A. Churchhill, J.E. Autrique, S.D. Tanksley, and M.E. Sorrells. 1993. Optimizing parental selection for genetic linkage maps. Genome 36:181-186.

Avise, J.C. 1994. Molecular markers, natural history, and evolution. Chapman and Hall, New York, NY.

Boutin-Ganache, I., M. Rapose, M. Raymond, and C.F. Descepper. 2001. M13-tailed primers improve the readability and usability of microsatellite analyses performed with two different allele-sizing methods. Biotechniques 31:1-3.

Evanno, G., S. Regnaut, and J. Goudet. 2005. Detecting the number of clusters of individuals using the software STRUCTURE: A simulation study. Mol. Ecol. 14:2611-2620.

Falush, D., M. Stephens, and J.K. Pritchard. 2003. Inference of population structure using multilocus genotype data: Linked loci and correlated allele frequencies. Genetics 164:1567-1587.

Falush, D., M. Stephens, and J.K. Pritchard. 2007. Inference of population structure using multilocus genotype data: Dominant markers and null alleles. Mol. Ecol. Notes 7:574-578.

Garcia, F. and A.B. Fite. 1931. Early grano onion culture. New Mexico Agr. Expt. Sta. Bul. 193.

Gaudeul, M., I. Till-Bottraud, F. Barjon, and S. Manel. 2004. Genetic diversity and differentiation in Eryngium alpinum L. (Apiaceae): Comparison of AFLP and microsatellite markers. Heredity 92:508518. 
Goldman, I.L., G. Schroeck, and M.J. Havey. 2000. History of public onion breeding programs and pedigree of public onion germplasm releases in the United States. Plant Breed. Rev. 20:67-103.

Gouesnard, B., T.M. Bataillon, G. Decoux, C. Rozale, D.J. Schoen, and J.L. David. 2001. MSTRAT: An algorithm for building germplasm core collections by maximizing allelic or phenotypic richness. J. Hered. 92:93-94.

Greene, S.L., T.J. Kisha, and N.I. Dzyubenko. 2008. Conserving alfalfa wild relatives: Is past introgression with Russian varieties evident today? Crop Sci. 48:1853-1864.

Havey, M.J. and O.H. Bark. 1994. Molecular confirmation that sterile cytoplasm has been introduced into open-pollinated Grano onion cultivars. J. Amer. Soc. Hort. Sci. 119:90-93.

Hu, J., O.E. Ochoa, M.J. Truco, and B.A. Vick. 2005. Application of the TRAP technique to lettuce (Lactuca sativa L.) genotyping. Euphytica 144:225-235.

Hu, J. and B. Vick. 2003. Target region amplification polymorphism: A novel marker technique for plant genotyping. Plant Mol. Biol. Rpt. 21:289-294.

Jakobsson, M. and N.A. Rosenberg. 2007. CLUMPP: A cluster matching and permutation program for dealing with label switching and multimodality in analysis of population structure. Bioinfomatics 23:1801-1806.

Jakše, J., W. Martin, J. McCallum, and M. Havey. 2005. Single nucleotide polymorphisms, indels, and simple sequence repeats for onion cultivar identification. J. Amer. Soc. Hort. Sci. 130:912-917.

Johnson, R.C., W.J. Johnston, C.T. Golob, M.C. Nelson, and R.J. Soreng. 2002. Characterization of the USDA Poa pratensis collection using RAPD markers and agronomic descriptors. Genet. Resources Crop Evol. 49:349-361.

Li, J. and C.F. Quiros. 2001. Sequence-related amplified polymorphism (SRAP), a new marker system based on a simple PCR reaction: Its application to mapping and gene tagging in Brassica. Theor. Appl. Genet. 103:455-461.

Magruder, R., R.E. Webster, H.A. Jones, T.E. Randall, G.B. Snyder, H.D. Brown, L.R. Hawthorn, and A.L. Wilson. 1941. Descriptions of types of principal American varieties of onions. U.S. Dept. Agr. Misc. Publ. 435.

Maher, C., L. Stein, and D. Ware. 2006. Evolution of Arabidopsis microRNA families through duplication events. Genome Res. 16: 510-519.

Mariette, S., V. Le Corre, F. Austerlitz, and A. Kremer. 2002. Sampling within the genome for measuring within population diversity: Trade-offs between markers. Mol. Ecol. 11:1145-1156.

Marita, J.M., J.M. Rodriguez, and J. Nienhuis. 2000. Development of an algorithm identifying maximally diverse core collections. Genet. Resources Crop Evol. 47:515-526.
Miklas, P.N., J. Hu, N.J. Grünwald, and K.M. Larsen. 2006. Potential application of TRAP (targeted region amplified polymorphism) markers for mapping and tagging disease resistance traits in common bean. Crop Sci. 46:910-916.

Nei, M. 1987. Molecular evolutionary genetics. Columbia Univ. Press, New York, NY.

Oliveira, E.J., J.G. Pádua, M.I. Zucchi, R. Vencovsky, and M.L.C. Vieira. 2006. Origin, evolution and genome distribution of microsatellites. Genet. Mol. Biol. 29:294-307.

Powell, W., M. Morgante, C. Andre, M. Hanafey, and J. Vogel. 1996. The comparison of RFLP, RAPD, AFLP, and SSR (microsatellite) markers for germplasm analysis. Mol. Breed. 2:225238.

Prevosti, A., J. Ocana, and G. Alonso. 1975. Distances between populations of Drosophila subobscura, based on chromosome rearrangement frequencies. Theor. Appl. Genet. 45:231-241.

Pritchard, J.K. and N.A. Rosenberg. 1999. Use of genetic markers to detect population stratification in association studies. Amer. J. Hum. Genet. 65:220-228.

Pritchard, J.K., M. Stephens, and P. Donnelly. 2000. Inference of population structure using multilocus genotype data. Genetics 155: 945-959.

Rosenberg, N.A. 2004. DISTRUCT: A program for the graphical display of population structure. Mol. Ecol. Notes 4:137-138.

Tautz, D. and M. Renz. 1984. Simple sequences are ubiquitous repetitive components of eukaryotic genomes. Nucleic Acids Res. 12:4127-4138.

U.S. Department of Agriculture. 2010. Query results for PI 546119. U.S. Dept. Agr., Agr. Res. Serv., National Germplasm Resources Lab. 17 Sept. 2010. <http://www.ars-grin.gov/cgi-bin/npgs/acc/ search.pl?accid $=546119>$.

van Treuren, R. and T.J.L. van Hintum. 2009. Comparison of anonymous and targeted molecular markers for the estimation of genetic diversity in ex situ conserved Lactuca. Theor. Appl. Genet. 119:1265-1279.

Volk, G.M., A. Henk, and C. Richards. 2004. Genetic diversity among U.S. garlic clones as detected using AFLP methods. J. Amer. Soc. Hort. Sci. 129:559-569.

Vos, P., R. Hogers, M. Bleeker, M. Reijans, T. van de Lee, M. Hornes, A. Frijters, J. Pot, J. Peleman, and M. Kuiper. 1995. AFLP: A new technique for DNA fingerprinting. Nucleic Acids Res. 23:44074414.

Woodhead, M., J. Rusell, J. Squirell, P.M. Hollingsworth, K. Mackenzie, M. Gibby, and W. Powell. 2005. Comparative analysis of population genetic structure in Athyrium distentifolium (Pteridophyta) using AFLPs and SSRs from anonymous and transcribed gene regions. Mol. Ecol. 14:1681-1695. 